OAK RIDGE

ORNL/TM-2002/161

NATIONAL LABORATORY

MANAGED BY UT-BATTELLE

FOR THE DEPARTMENT OF ENERGY

\title{
EVALUATION OF CORROSION FAILURE IN \\ TRACTOR-TRAILER BRAKE SYSTEM
}

July 2002

D. F. Wilson, E. A. Kenik, P. J. Blau

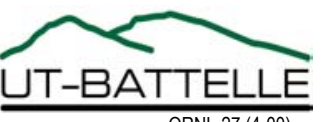




\section{DOCUMENT AVAILABILITY}

Reports produced after January 1, 1996, are generally available free via the U.S. Department of Energy (DOE) Information Bridge.

Web site http://www.osti.gov/bridge

Reports produced before January 1, 1996, may be purchased by members of the public from the following source.

National Technical Information Service

5285 Port Royal Road

Springfield, VA 22161

Telephone 703-605-6000 (1-800-553-6847)

TDD 703-487-4639

Fax 703-605-6900

E-mail info@ntis.fedworld.gov

Web site http://www.ntis.gov/support/ordernowabout.htm

Reports are available to DOE employees, DOE contractors,

Energy Technology Data Exchange (ETDE) representatives, and International Nuclear Information System (INIS)

representatives from the following source.

Office of Scientific and Technical Information

P.O. Box 62

Oak Ridge, TN 37831

Telephone 865-576-8401

Fax 865-576-5728

E-mail reports@adonis.osti.gov

Web site http://www.osti.gov/contact.html

This report was prepared as an account of work sponsored by an agency of the United States Government. Neither the United States Government nor any agency thereof, nor any of their employees, makes any warranty, express or implied, or assumes any legal liability or responsibility for the accuracy, completeness, or usefulness of any information, apparatus, product, or process disclosed, or represents that its use would not infringe privately owned rights. Reference herein to any specific commercial product, process, or service by trade name, trademark, manufacturer, or otherwise, does not necessarily constitute or imply its endorsement, recommendation, or favoring by the United States Government or any agency thereof. The views and opinions of authors expressed herein do not necessarily state or reflect those of the United States Government or any agency thereof. 
Metals and Ceramics Division

\title{
EVALUATION OF CORROSION FAILURE IN \\ TRACTOR-TRAILER BRAKE SYSTEM
}

\author{
D. F. Wilson \\ E. A. Kenik \\ P. J. Blau
}

Date Published: July 2002

Prepared for the

U.S. Department of Energy

Assistant Secretary for Energy Efficiency and Renewable Energy

Office of FreedomCAR and Vehicle Technologies

High Strength Weight Reduction Materials Program

EE 0702000

Prepared by

OAK RIDGE NATIONAL LABORATORY

Oak Ridge, Tennessee 37831-6285

managed by

UT-Battelle, LLC

for the

U.S. DEPARTMENT OF ENERGY

under contract DE-AC05-00OR22725 



\section{CONTENTS}

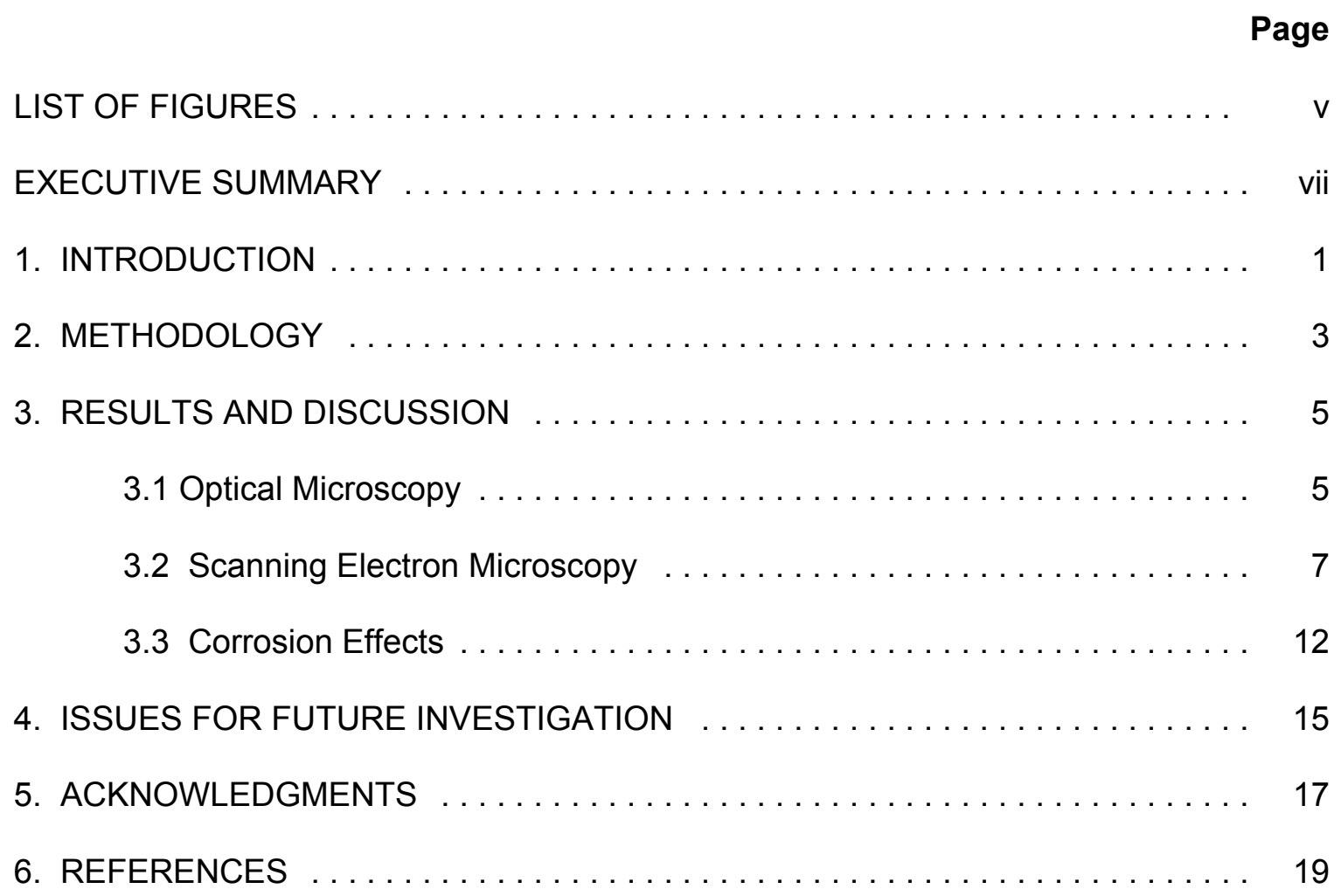



1. Brake shoe table and lining showing corrosion product on the table, separation of lining from table and cracking of the lining

2. Partially disassembled brake system showing shoe table, lining and layout of rivet and ancillary holes $\ldots \ldots \ldots \ldots \ldots \ldots \ldots \ldots \ldots \ldots \ldots \ldots$

3. Layout of sites on the brake table that were sectioned for evaluation $\ldots \ldots \ldots \quad 4$

4. Typical appearance of cross section showing non-uniform corrosion at the brake tablellining interface $\ldots \ldots \ldots \ldots \ldots \ldots \ldots \ldots \ldots \ldots$

5. Higher magnification image showing details of the non-uniform corrosion $\ldots \ldots 6$

6. Cross-section across a rivet hole showing relatively smooth surface of the surface that was not in contact with the brake lining $\ldots \ldots \ldots \ldots$

7. Higher magnification image of the surface that was not in contact with the lining shows a delineation of the shoulder of the rivet hole $\ldots \ldots \ldots \ldots \ldots$

8. Secondary electron image of the spalled scale showing banding,

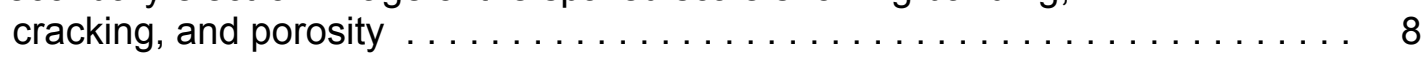

9. Backscattered electron image revealed light $\left(\mathrm{Fe}_{3} \mathrm{O}_{4}\right)$ and dark $\left(\mathrm{Fe}_{2} \mathrm{O}_{3}\right)$

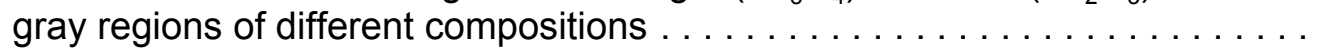

10. X-ray spectrum of light gray area showing a lower O/Fe ratio as compared to the spectrum for the dark gray area

11. X-ray spectrum of the dark gray area showing a higher $\mathrm{O} / \mathrm{Fe}$ ratio as compared to that for the light gray area .................. 9

12. Backscattered image showing scale attached and spalled areas $\ldots \ldots \ldots \ldots$

13. Backscattered image showing banding in the adherent scale $\ldots \ldots \ldots \ldots$

14. X-ray spectrum of attached (dark gray) scale showing the presence of sodium,

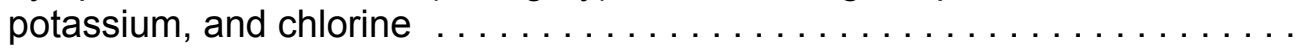





\section{EXECUTIVE SUMMARY}

As reported to ORNL, concomitant with the introduction of different deicing and anti-icing compounds, there was an increase in the brake failure rate of tractor-trailer trucks. A forensic evaluation of a failed brake system was performed. Optical and scanning electron microscopic evaluation showed corrosion to be mostly confined to the brake table/lining interface. The corrosion is non-uniform as is to be expected for plain carbon steel in chloride environments. This initial analysis found no evidence for the chlorides of calcium and magnesium, which are the newly introduced deicing and antiicing compounds and are less soluble in water than the identified chlorides of sodium and potassium, in the scale. The result could be as a result of non-exposure of the examined brake table to calcium and magnesium chloride.

The mechanisms for the increased failure rate are postulated as being an increased rate of corrosion due to positive shifts in the corrosion potential, and an increased amount of corrosion due to an increased "time of wetness" that results from the presence of hygroscopic salts. Laboratory scale evaluation of the corrosion of plain carbon steel in simulated deicing and anti-icing solutions need to be performed to determine corrosion rates and morphological development of corrosion product, to compare laboratory data to in-service data, and to rank economically feasible replacement materials for low carbon steel. In addition, the mechanical behavior of the lining attached to the brake shoe table needs to be assessed. It is opined that an appropriate adjustment of materials could easily allow for a doubling of a brake table/lining lifetime. Suggestions for additional work, to clarify the mechanisms of rust jacking and to develop possible solutions, are described. 



\section{INTRODUCTION}

The long-haul trucking industry has been experiencing extensive corrosion of its equipment. While this corrosion affects many parts of the tractor-trailer rig, one of the greatest concerns is that associated with the brakes, specifically, what has been termed "Rust Jacking." The proposed mechanism involves the corrosion of the brake shoe table (see Fig. 1), which results in the buildup of corrosion products between it and the brake lining to which it is riveted. This accumulation of corrosion products causes the brake lining to crack. Should this cracking, see Fig. 1, be found by the various Departments of Transportation, rather than the fleet maintenance personnel, the fleet company will be ticketed.
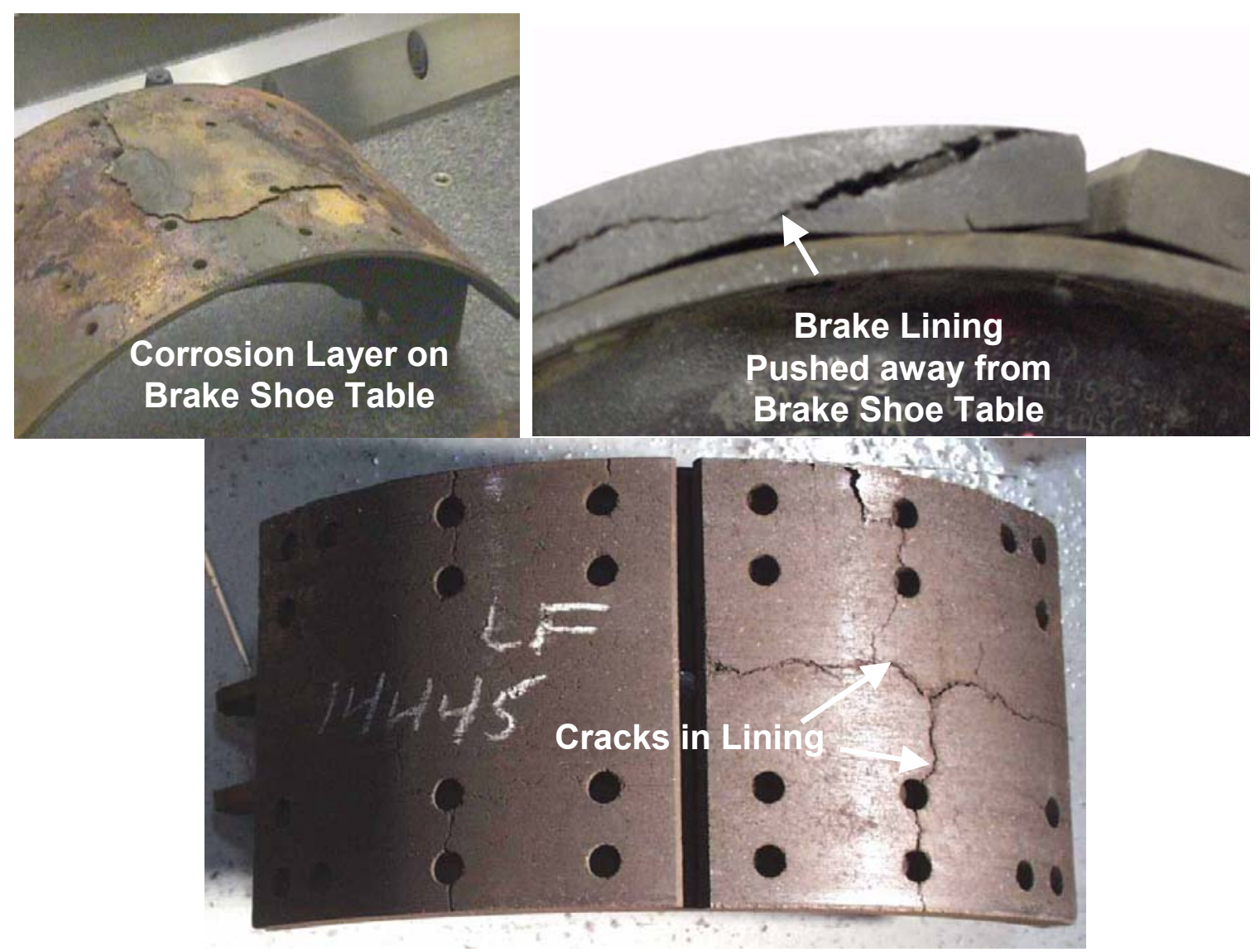

Fig. 2. Brake shoe table and lining showing corrosion product on the table, separation of lining from table and cracking of the lining. 
In recent years, the frequency of this type of brake failure has doubled coincidently with use of increasingly more complex mix of anti-icing and deicing compounds. At present, some combination of solids such as sand, gravel and course salt, and liquid solutions of magnesium, calcium, and sodium chlorides, and calciummagnesium and potassium acetates are employed in various states. Many long-haul trucks, therefore, are exposed to a variety of deicing and anti-icing compounds in various concentrations, exposure order and combinations. While brake failure is reported to have increased, it is unclear how the new exposure factors contribute to the failure mode and rate. 


\section{METHODOLOGY}

A failed brake shoe table assembly was received from Truck It, Incorporated, Franklin, Kentucky, with the assistance of Roy Gambrell, Director of Maintenance. The as-received assembly had the rivets removed prior to arrival at the Oak Ridge National Laboratory. A photograph of the partially disassembled brake shoe table and lining is shown in Fig. 2, which also shows the pattern of rivet and other holes in the brake table. The brake shoe table was sectioned in the areas designated as " $A$ " through " $F$ " in Fig. 3. These sections, along with a section of corrosion product that separated from the shoe table, were metallographically prepared. All sections, except the latter, were etched with $2 \%$ nital solution and examined using optical microscopy. Two cross-sections and the corrosion product section were also examined using a scanning electron microscope and associated energy dispersive spectrometer.

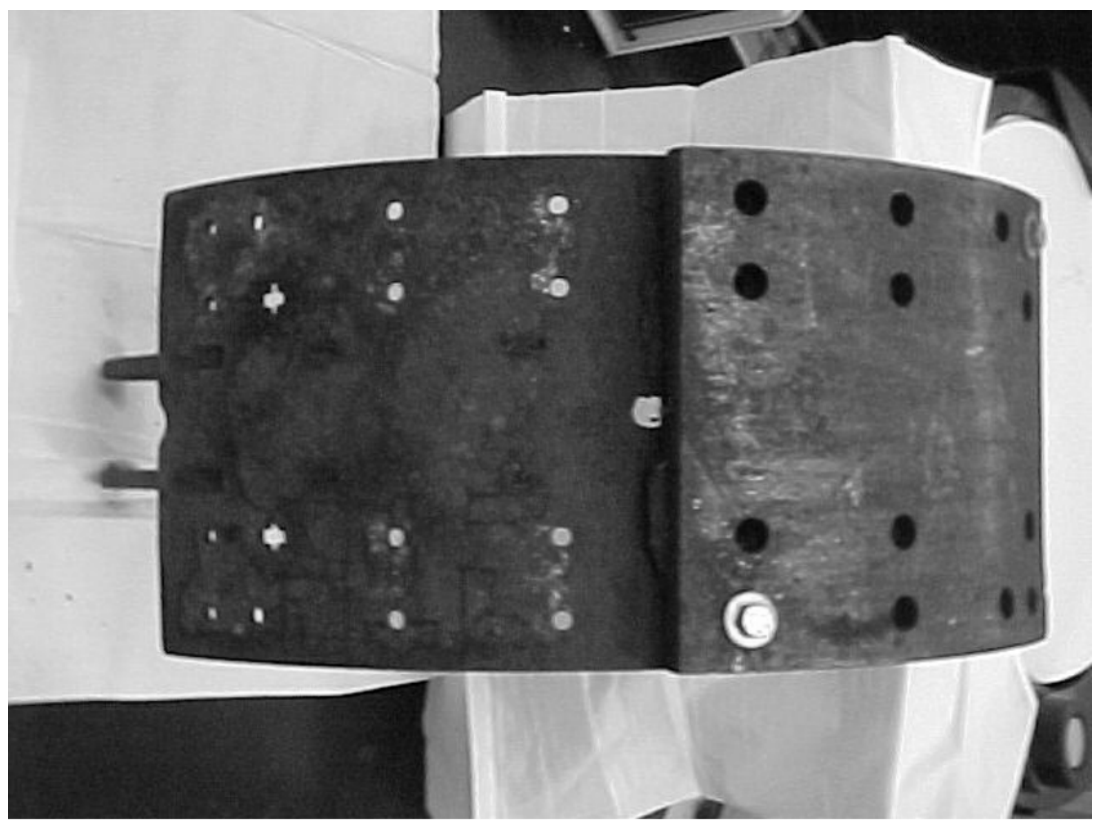

02-2026-02

Brake Shoe

Fig. 3. Partially disassembled brake system showing shoe table, lining and layout of rivet and ancillary holes. 


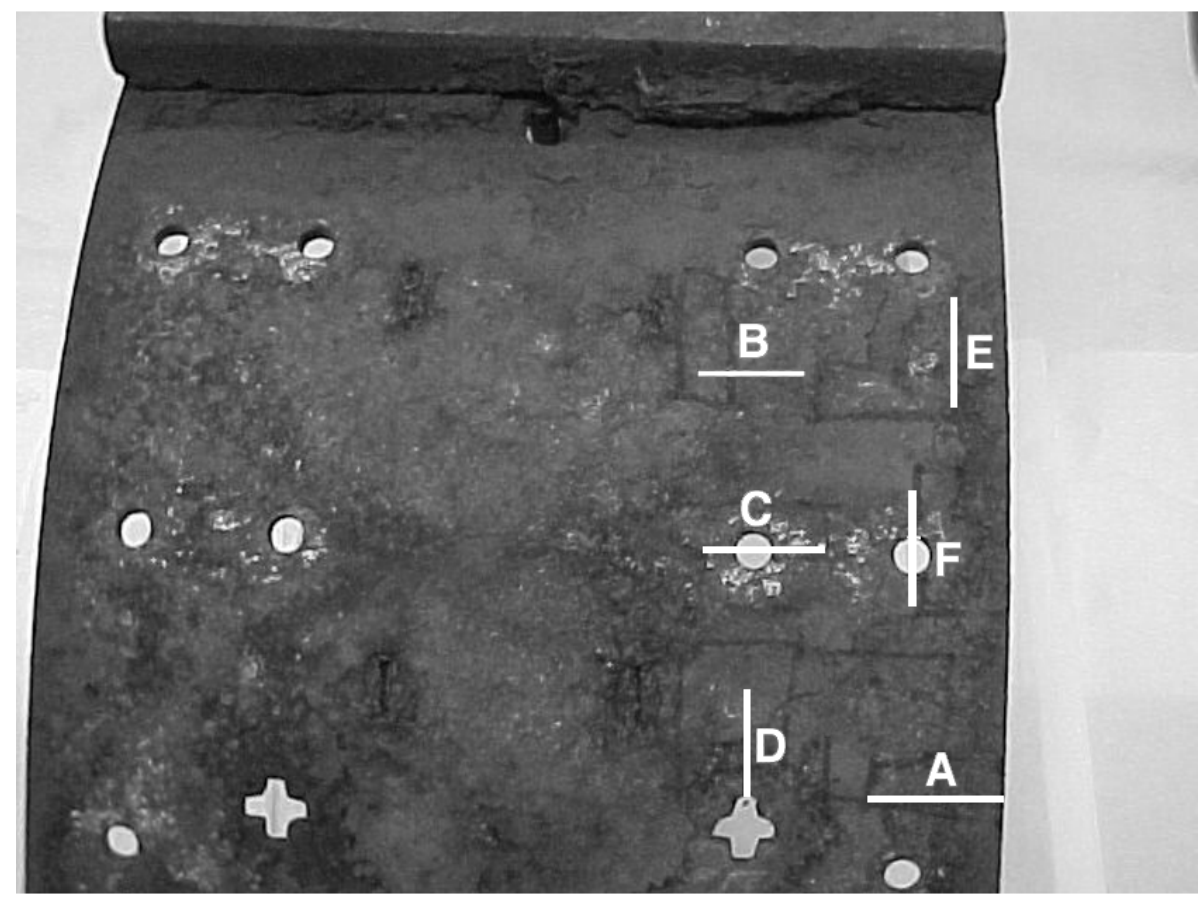

02-2026-04

Brake Shoe

Fig. 4. Layout of sites on the brake table that were sectioned for evaluation. Transverse sections are from sites A, B, and C, and longitudinal section are from and sites $\mathrm{D}, \mathrm{E}$, and $\mathrm{C}$. 


\section{RESULTS AND DISCUSSION}

\subsection{Optical Microscopy}

Optical examination of the cross sections of the shoe table material revealed a typical plain carbon steel structure with corrosion occurring at the brake shoe table/lining interface as shown in Fig. 4. As displayed in Figs. 4 and 5, the corrosion at the table/lining interface is non-uniform as is to be expected for a plain carbon steel exposed to chloride environment. The surface of the brake table that was not in contact with the lining was still relatively smooth (Fig. 6) and the shoulder on the rivet hole is clearly delineated (Fig. 7).

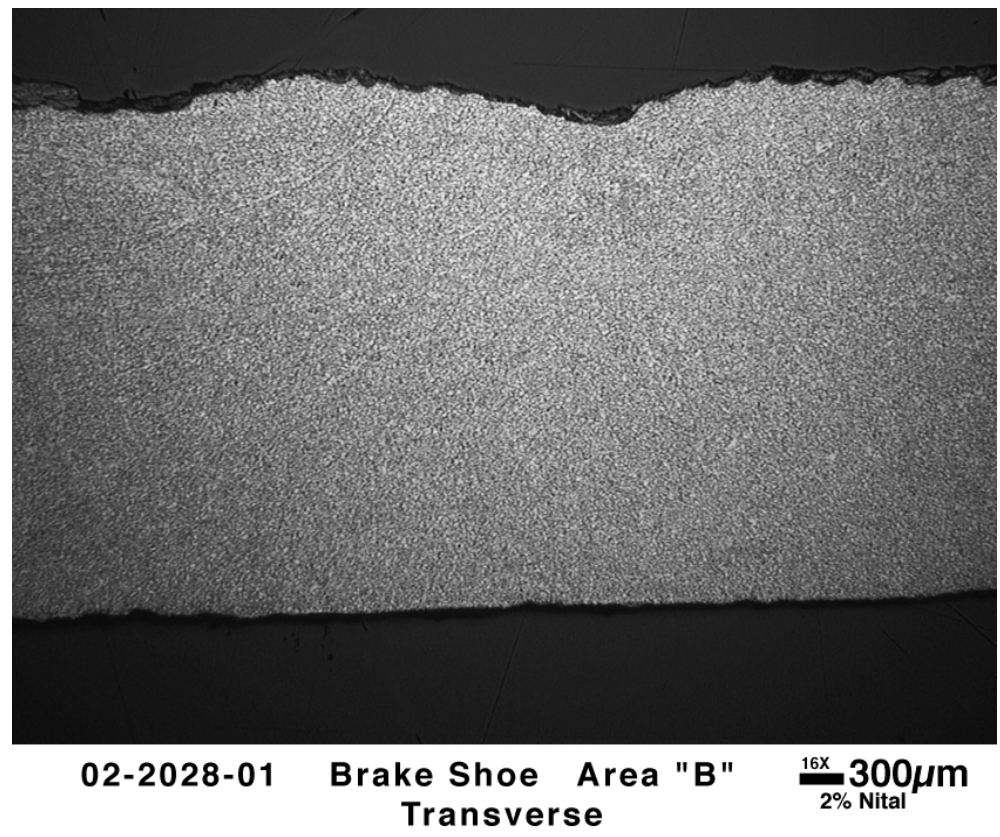

Fig. 5. Typical appearance of cross section showing non-uniform corrosion at the brake tablellining interface (top of picture). 


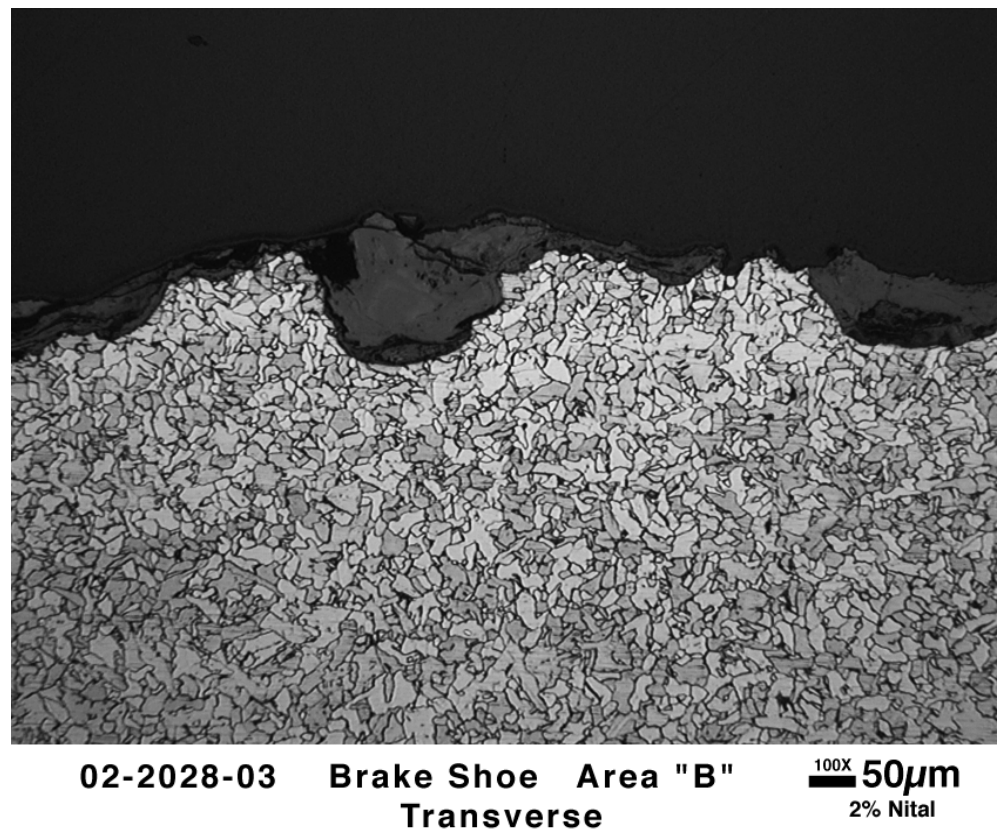

Fig. 6. Higher magnification image showing details of the non-uniform corrosion.

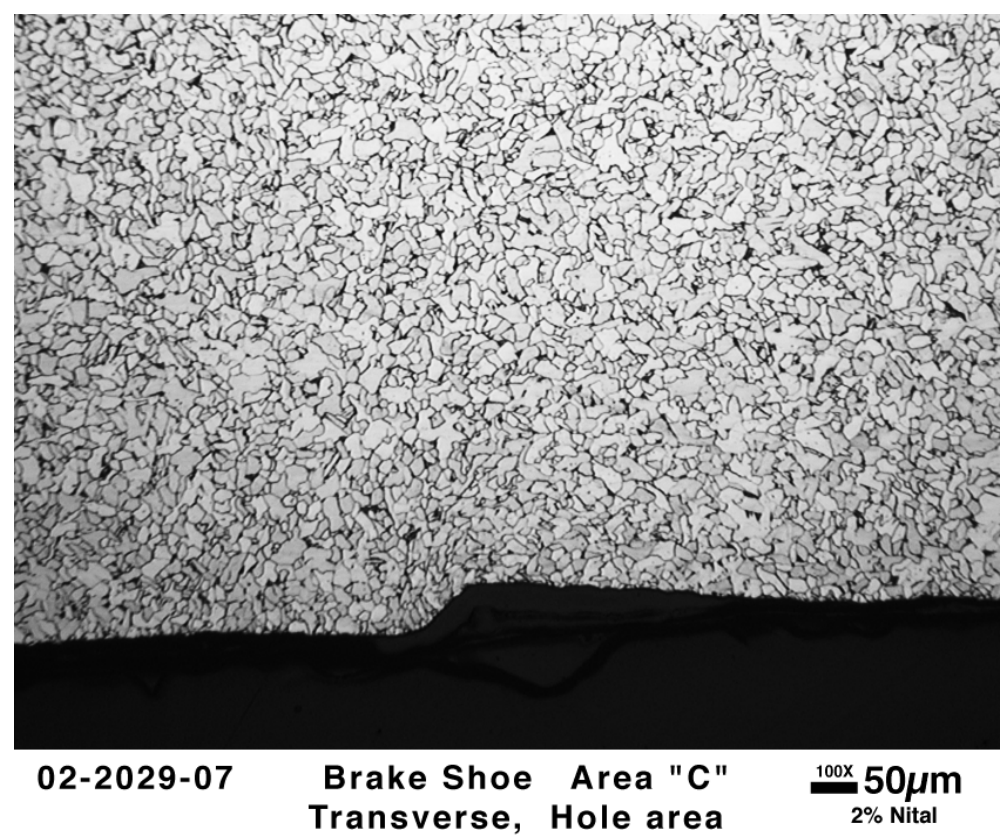

Fig. 7. Cross-section across a rivet hole showing relatively smooth surface of the surface that was not in contact with the brake lining. 


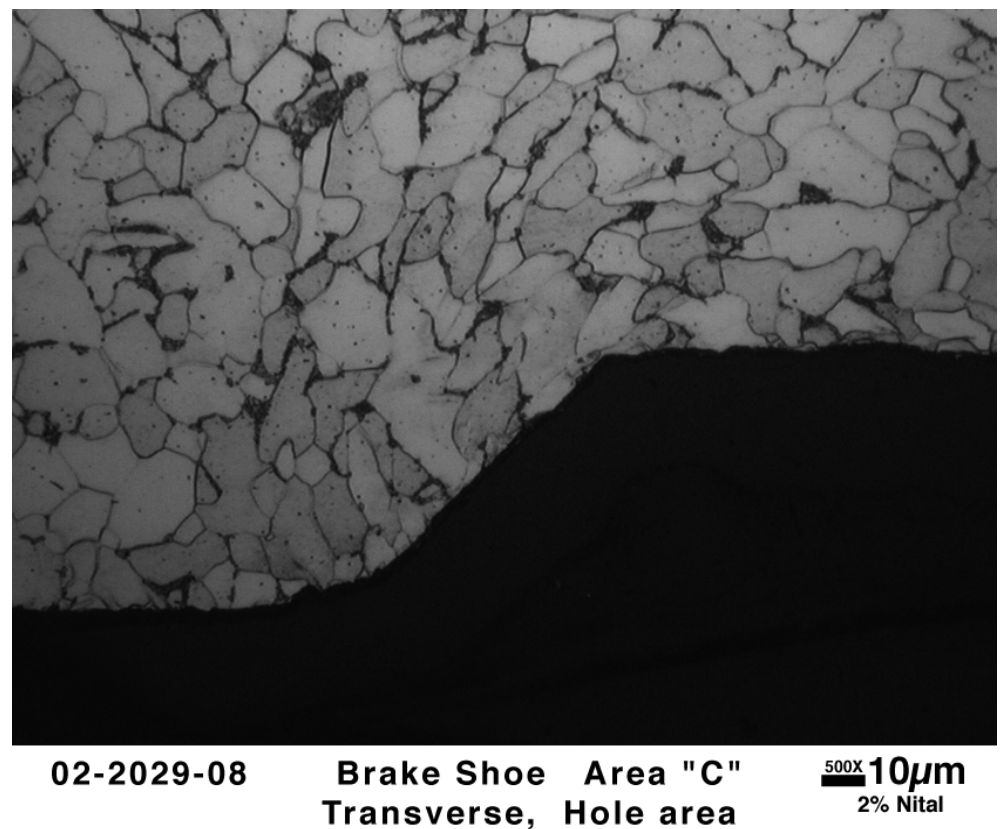

Fig. 8. Higher magnification image of the surface that was not in contact with the lining shows a delineation of the shoulder of the rivet hole.

\subsection{Scanning Electron Microscopy}

Scanning electron microscopy (SEM) and x-ray microanalysis were used to examine the structure and composition of the oxide scale from the supplied brake table. Both a spalled piece of the scale and the adherent scale on the metal table were studied. A secondary electron (SE) image, Fig. 8, shows that the scale was banded parallel to the original metal interface and contained both porosity and cracks. The corresponding backscattered electron (BSE) image, Fig. 9, revealed local differences in composition. X-ray microanalysis in the SEM showed that the light gray oxide regions were the Fe-rich $\mathrm{Fe}_{3} \mathrm{O}_{4}$ oxide; whereas the dark gray regions were the Fe-poor $\mathrm{Fe}_{2} \mathrm{O}_{3}$ oxide. The ratio of the O/Fe peaks is lower for the light gray oxide, x-ray spectrum shown in Fig. 10, relative to that for the dark gray oxide, $\mathrm{x}$-ray spectrum shown in Fig. 11. Trace amounts on $\mathrm{Cl}$ were found in the scale. Though there were variations in $\mathrm{Cl}$ levels, there was no obvious 
preference for $\mathrm{Cl}$ by either oxide phase. The occasional presence of Si was derived presumably from an inhomogeneous distribution of Si in the alloy.

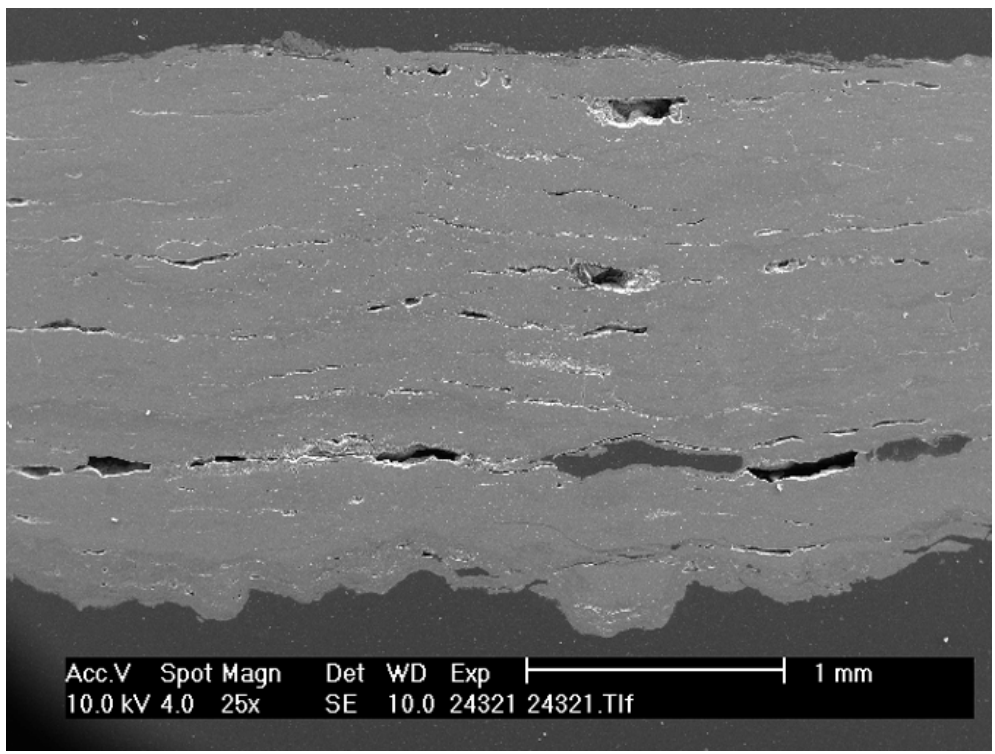

Fig. 9. Secondary electron image of the spalled scale showing banding, cracking, and porosity.

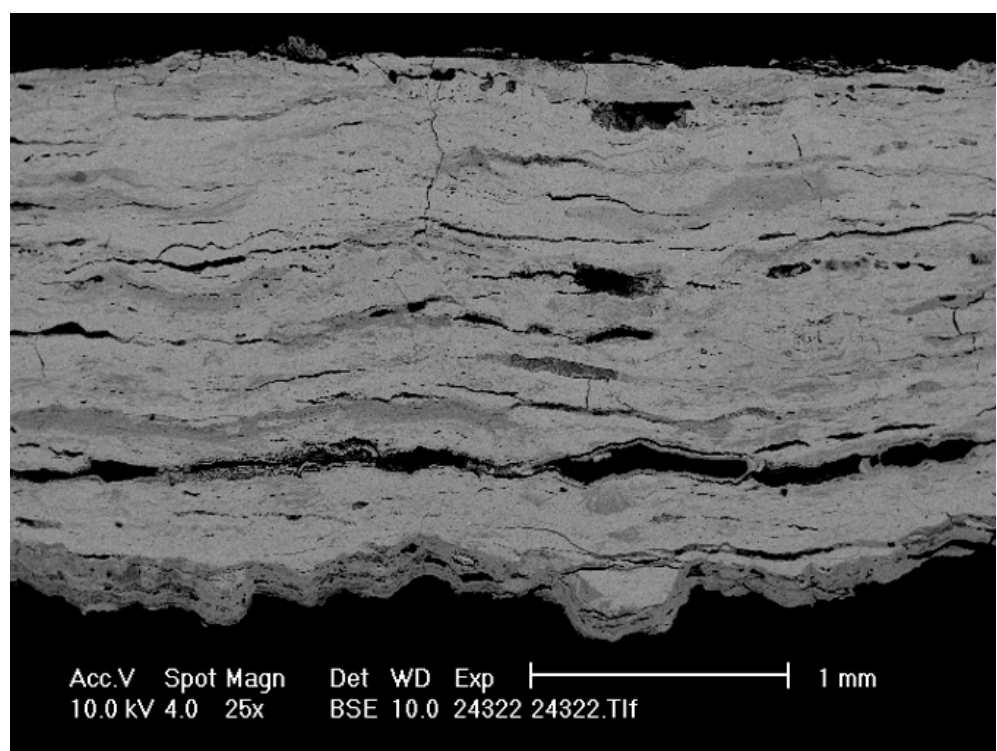

Fig. 10. Backscattered electron image revealed light $\left(\mathrm{Fe}_{3} \mathrm{O}_{4}\right)$ and dark $\left(\mathrm{Fe}_{2} \mathrm{O}_{3}\right)$ gray regions of different compositions. 


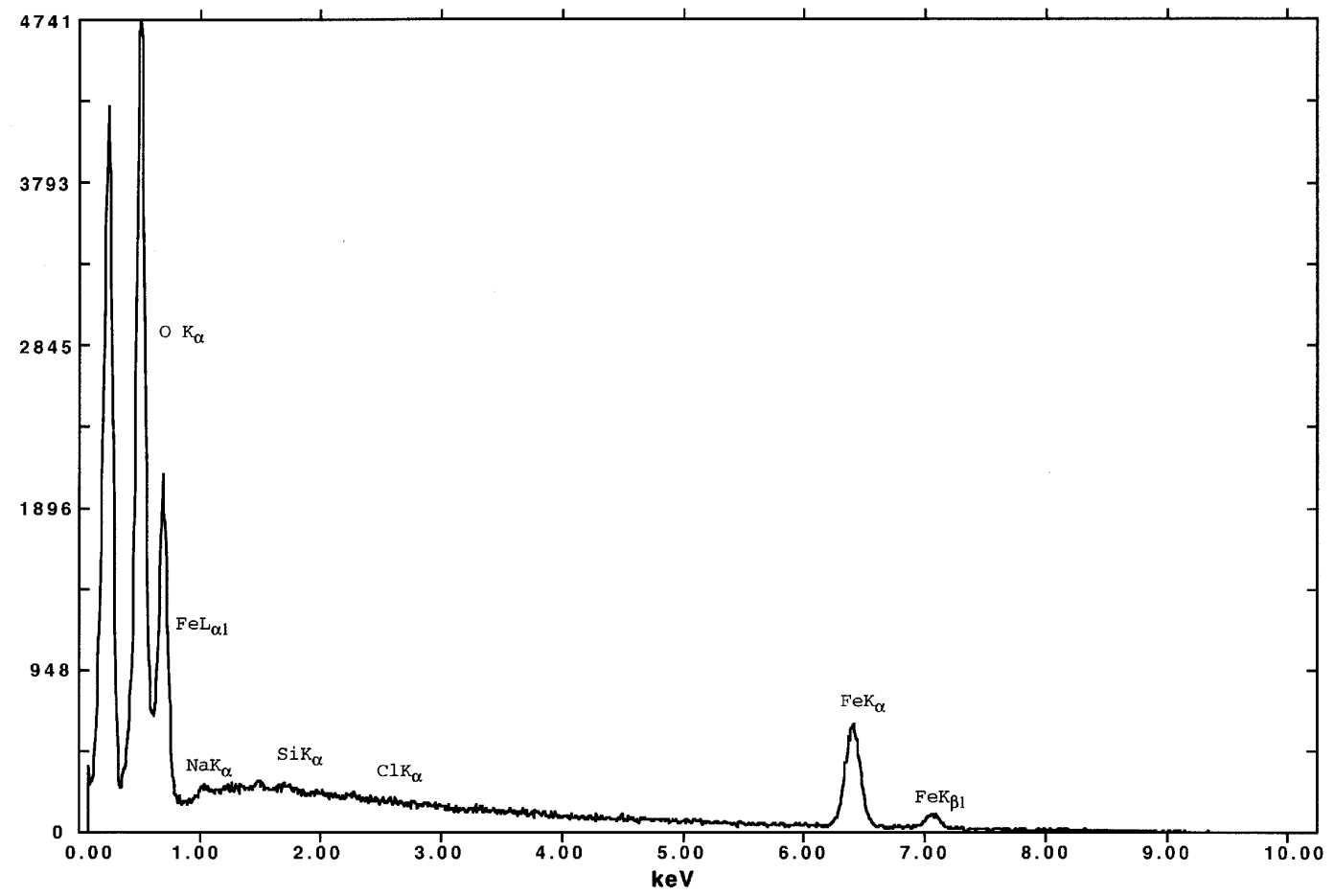

Fig. 11. X-ray spectrum of light gray area showing a lower $\mathrm{O} / \mathrm{Fe}$ ratio as compared to the spectrum for the dark gray area (following figure).

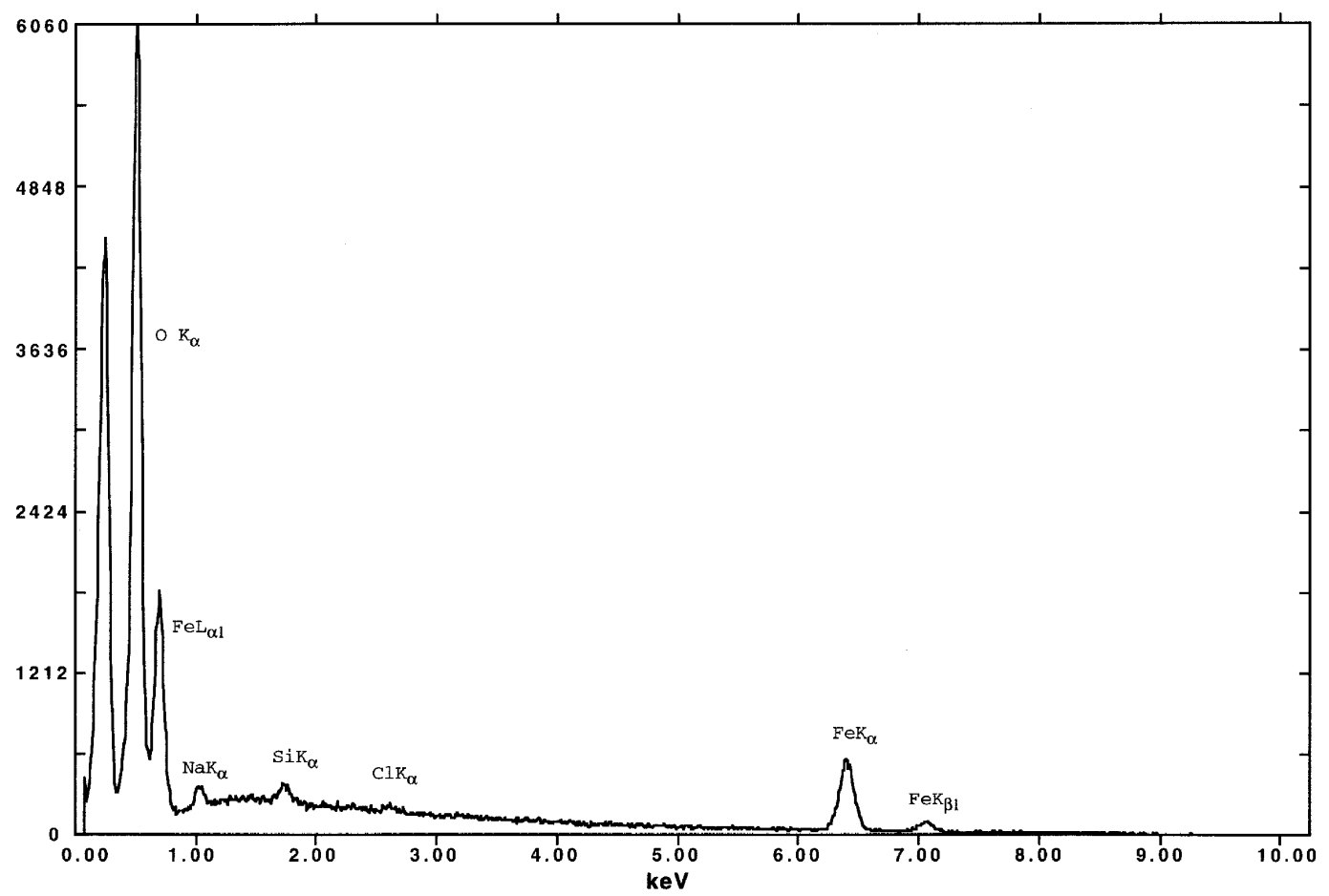

Fig. 12. X-ray spectrum of the dark gray area showing a higher O/Fe ratio as compared to that for the light gray area (previous figure). 
A region of the adherent scale near a hole in the metal table was examined in the SEM. As shown in Fig. 12, there are regions of adherent oxide and regions where the oxide has completely spalled off, leaving bare metal exposed. The adherent scale exhibited similar banding of the oxides, Fig. 13, where the bright phase at the top of the BSE image is the metal table. X-ray microanalysis on both oxides indicated increased levels of the minor elements, $\mathrm{Na}, \mathrm{Cl}$, and $\mathrm{K}$. An x-ray spectrum, Fig. 14, shows the minor impurities at a defect in the dark oxide, which showed slightly elevated impurity levels relative to the bulk of the oxide. Note that the vertical scale has been expanded to highlight the impurity peaks. The presence of $\mathrm{Mn}$ and $\mathrm{S}$ is taken to indicate the presence of a MnS inclusion from the original steel that has been incorporated in the oxide. The inclusion has increased the local concentration of $\mathrm{Na}, \mathrm{Cl}$, and $\mathrm{K}$. No $\mathrm{Mg}$ or $\mathrm{Ca}$ was detected in either the spalled or adherent scales. It is interesting to note that the more likely water-soluble impurities $(\mathrm{Na}, \mathrm{Cl}$, and $\mathrm{K})$ are present in the scales; whereas the less soluble impurities ( $\mathrm{Mg}$ and $\mathrm{Ca}$ ) are not present. Of course, this observation could simply reflect the actual exposure this particular brake assembly received.

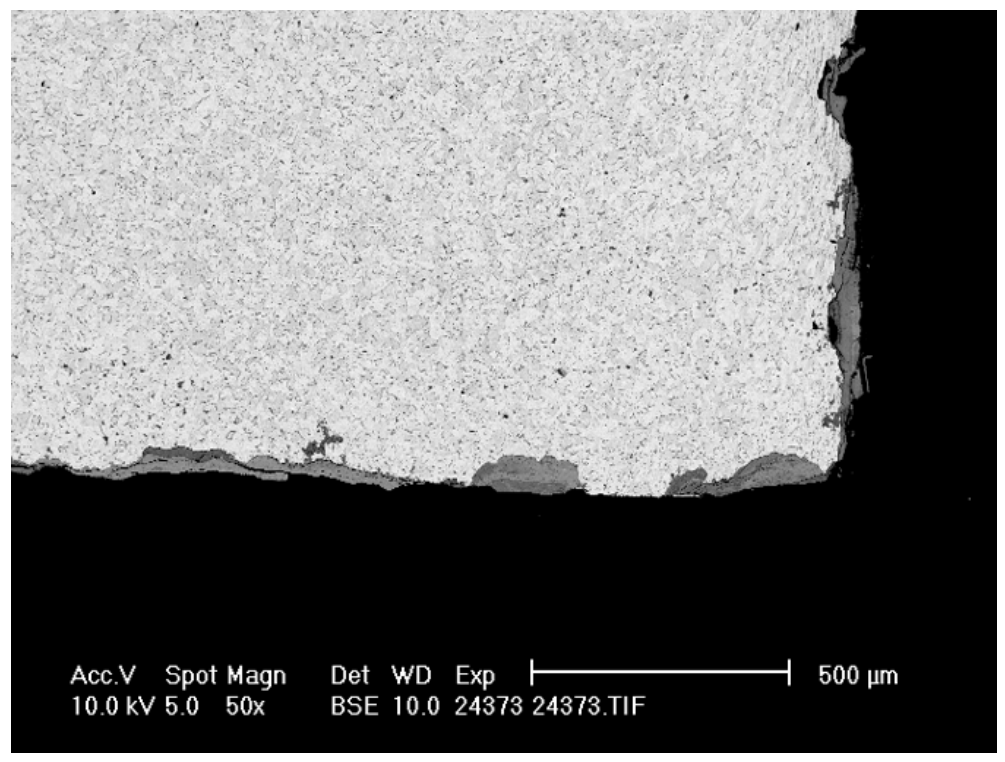

Fig. 13. Backscattered image showing scale attached and spalled areas. 


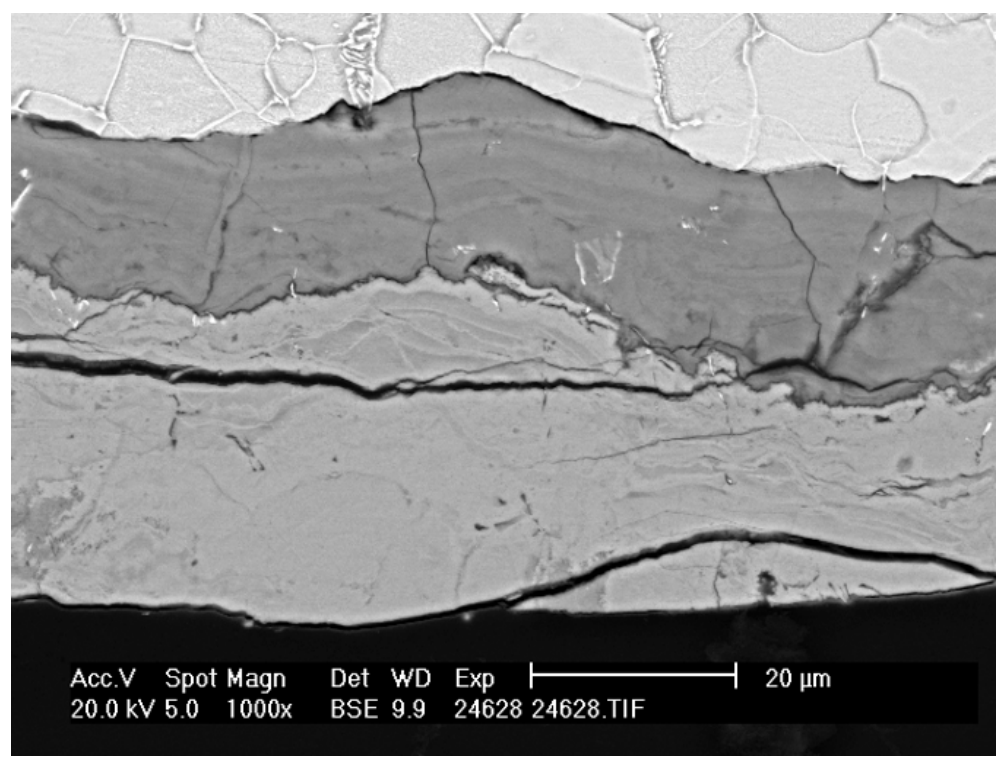

Fig. 14. Backscattered image showing banding in the adherent scale. The light region at the top of the scale is plain carbon steel, the middle dark gray region is $\mathrm{Fe}_{2} \mathrm{O}_{3}$, and the bottom light gray region is $\mathrm{Fe}_{2} \mathrm{O}_{4}$.

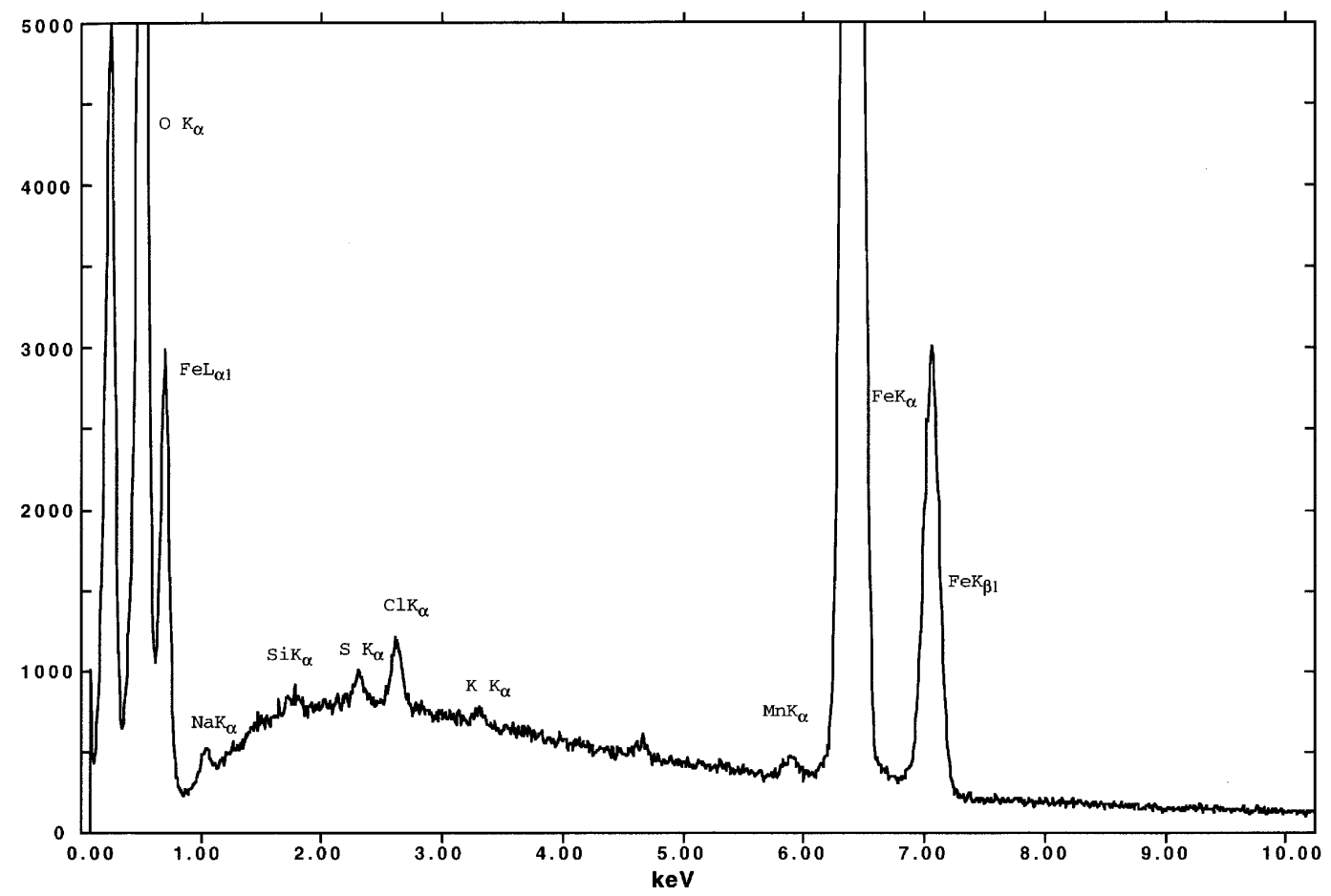

Fig. 15. X-ray spectrum of attached (dark gray) scale showing the presence of sodium, potassium, and chlorine. The manganese and sulfur are assumed to arise from inclusions. 


\subsection{Corrosion Effects}

As reported to ORNL, concomitant with the introduction of different deicing and anti-icing compounds, there was an increase in the brake failure rate. This initial analysis found no evidence for the chlorides of calcium and magnesium, which are less soluble in water than the identified chlorides of sodium and potassium, in the scale. While this can be due to the vehicle having not been used in states that use calcium and magnesium, it is also possible that the corrosion products that form in the presence of calcium and magnesium are more friable and were readily lost once the lining was removed from the brake table.

The banding of the oxide scale may reflect the changing corrosion conditions to which the brakes are exposed. Variations in composition and concentration of anti-icing and deicing salts, $\mathrm{pH}$, moisture, temperature, and frequency and pressure of braking could all impact the corrosion rate and resultant products. Salt composition and concentration, and $\mathrm{pH}$, which affect the corrosion potential of the plain carbon steel, are the major contributors to the banding. A small change in salt composition and/or concentration, with or without a slight change in $\mathrm{pH}$, can result in shifts between $\mathrm{Fe}_{3} \mathrm{O}_{4}$ and $\mathrm{Fe}_{2} \mathrm{O}_{4}$ phase fields, as can be inferred from the potential-pH equilibrium diagram for the iron-water system. ${ }^{1}$ In addition, increasing the corrosion potential results in an increased corrosion rate. Furthermore, while the chlorides of sodium and potassium are not hygroscopic, the chlorides of magnesium and calcium, and the acetates of calcium, magnesium, and potassium are hygroscopic. ${ }^{2}$ Thus the recently introduced anti-icing and deicing compounds results in increased "time of wetness," and hence, increased corrosion. Moreover, cracking, porosity, and localized spalling of the scale would 
provide new pathways for water ingress and exposure of fresh metal to the corrosive environment.

The mechanisms for the increased failure rate are postulated as being an increased rate of corrosion due to positive shifts in the corrosion potential, and an increased amount of corrosion due to an increased "time of wetness" that results from the presence of hygroscopic salts. Laboratory scale evaluation of the corrosion of plain carbon steel in simulated deicing and anti-icing solutions needs to be performed to determine corrosion rates and morphological development of corrosion products, to compare laboratory data to in-service data, and to rank economically feasible replacement materials or coatings for low carbon steel. In addition, the mechanical behavior of the lining attached to the brake shoe table needs to be assessed. It is opined that suitable adjustment of materials could easily allow for a doubling of brake table/lining lifetime. 



\section{ISSUES FOR FUTURE INVESTIGATION}

The results of this initial evaluation identified some standard effects related to chloride corrosion of plain carbon steel and their potential detrimental effects on brake systems. While not surprising, these results suggest future laboratory scale investigations that may lead to cost effective improvements in the brake assembly. These proposed investigations should include forensic analyses, corrosion testing and materials selection, determination of properties of lining material, determination of the elastic properties of oxides, and modeling of rust jacking stresses.

- Forensic Analyses. Further forensic analyses of failed brake shoes will permit an assessment of the extent of corrosion, and identification of aggressive species that are incorporated into the corrosion product. This information will guide the selection of alternate materials and coatings, and the preparation of test solutions.

- Corrosion Testing and Materials Selection. Samples of the present material of construction of the brake shoe table, and appropriately chosen materials that would be economically viable replacements should be evaluated in simulated deicing environments. The data generated would allow for selection of appropriate, cost effective materials and coatings for future brake shoe manufacture, and comparison of the effect of various deicing compounds on corrosion rates.

- Properties of Lining Material. The mechanical properties of flexure strength specimens, cut from commercial drum brake lining materials, should be measured at several temperatures to assess their dependence on the friction-induced 
temperature rise in brakes. These mechanical properties will include the flexure stress-strain behavior, fracture stress, and elastic modulus. The information from these tests will be used in the proposed modeling task.

- Elastic Properties of Oxides. The elastic moduli of specimens of the dominant oxides involved in rust jacking should be determined. These measurements can be readily performed using instrumented indentation tests, which are available in the High Temperature Materials Laboratory, at ORNL. Where oxides occur in layers, estimates can be made of the effective elastic properties of the lamellar structure. This information will be used in the modeling task.

- Modeling of Rust Jacking Stresses. Advanced analytical models, including stressanalysis by finite-element techniques should be developed to predict the stresses on the back-side of the lining associated with swelling of oxides in the shoe/lining interface. The influence of pinning by lining fasteners (rivets) must be included in this model. Lining and oxide property data, obtained in the previous task, will be used as inputs for the model. Critical conditions for lining fracture will be calculated as a function of rivet spacing, oxide swell and related conditions. 


\section{ACKNOWLEDGMENTS}

The authors acknowledges the assistance of $\mathrm{H}$. F. Longmire for excellent metallography and F. C. Stooksbury for preparation of this manuscript and paperwork associated with this project. 



\section{REFERENCES}

1. Marcel Pourbaix, Atlas of Electrochemical Equilibria in Aqueous Solution, p. 312, 1974, NACE International, Houston, Texas.

2. David R. Lide, Editor in Chief, Handbook of Chemistry and Physics, $82^{\text {nd }}$ edition, 2001, CRC Press, New York. 

ORNL/TM-2002/161

\section{INTERNAL DISTRIBUTION}

1-2. P. J. Blau

3-4. E. A. Kenik

5. S. J. Pawel

6-7. P. S. Sklad

8. P. F. Tortorelli
9-13. D. F. Wilson

14. Central Research Library

15. ORNL Laboratory Records-RC 16-17. ORNL Laboratory Records-OSTI

\section{EXTERNAL DISTRIBUTION}

18-19. Sidney Diamond, Program Manager, U.S. Department of Energy, EE-2G, Forrestal Building, 1000 Independence Avenue SW, Washington, DC 20585

20-21. Roy Gambrell, Director of Maintenance, Truck It Incorporated, P. O. Box 713, Franklin, KY 42135

22-23. Tom Newby, Old Dominion Freight Lines, Maintenance Department, 500 Old Dominion Way, Thomasville, NC 27360 
